\title{
Pengembangan Social Emotional Competencies melalui Outdoor Education
}

\section{Development of Social Emotional Competencies through Outdoor Education}

\author{
Muhammad Ihsan, Amung Ma'mun \& Ucup Yusup \\ Universitas Pendidikan Indonesia, Bandung, Jawa Barat, Indonesia \\ muhammadihsan@upi.edu, amung@upi.edu,\& ucupyusup@upi.edu
}

Naskah diterima tanggal 02/06/2019, direvisi akhir tanggal 24/06/2019, disetujui tanggal 31/07/2019

\begin{abstract}
Abstrak
Tujuan dari penelitian ini untuk mengetahui apakah terdapat pengaruh dari program outdoor education diintegrasi social emotional learning terhadap pengembangan social emotional competencies. Metode penelitian eksperimen dengan desain pretest-posttest control group design with more than one experimental group digunakan dalam penelitian ini. Hasil penelitian menunjukan bahwa program outdoor education integrasi social emotional learning terstruktur secara terencana memiliki hasil dan pengaruh signifikan terhadap pengembangan social emotional competencies. Selanjutnya, guru pendidikan jasmani dapat menggunakan program terstruktur secara terencana untuk pengembangan aspek afektif melalui berbagai aktivitas outdoor education.
\end{abstract}

Kata kunci: Integrasi, Outdoor Education, Social Emotional Competencies

\section{Abstract}

The purpose of this study is to find out whether there is influence from the outdoor education program integrated with social emotional learning towards the development of social emotional competencies. The experimental research method with the design of the pretest-posttest control group design with more than one experimental group was used in this study. Result indicated that outdoor education program with intentionally sturctured with integrating process there was a significantly influence to develop social emotional competencies. Furthermore, PE teachers can use this intentionally structured program to develop affective aspect through outdoor education activities.

Keywords: Integrating, Outdoor Education, Social Emotional Competencies

\section{PENDAHULUAN}

Dalam 20 tahun terakhir, outdoor education $(O E)$, menunjukkan sejumlah pengaruh positif pada pengembangan pribadi dan sosial, aktivitas fisik, pencapaian akademik, dan keterampilan kepemimpinan untuk berbagai usia. Outdoor education (OE) bertujuan untuk mendorong pembelajaran melalui interaksi antara emosi, tindakan dan pemikiran, berdasarkan pengamatan praktis dalam situasi otentik (Szczepanski, 2009). Outdoor education $(O E)$ menggambarkan manfaat seperti kepercayaan diri (self-confidence) lebih besar, kemandirian (independence) dan ketahanan (resilience), dan persahabatan erat (strengthened friendships) dan keterlibatan pembelajaran (school engagement) (Williams, Rose, Olsson, Patton, \& Allen, 2018). Di Singapura, penelitian tentang outdoor education $(O E)$ dimulai pada tahun 
1967. Outdoor education (OE) dipandang sebagai dasar dan pedoman pendidikan di Singapura Martin \& Ho (2009); Kendall, Rodger, \& Laxton (2015); Richmond, Sibthorp, Gookin, Annarella, \& Ferri (2018) memaparkan berbagai dampak positif outdoor education (OE) dalam bidang psikososial, emosional, fisik, spiritual, dan pendidikan. Ini termasuk peningkatan selfefficacy, improved self-esteem, internal locus of control, strengthened personal autonomy dan selfdetermination, pertumbuhan dan pengembangan hubungan interpersonal dan keterampilan sosial, depression serta anxiety (Vroegop, 2014; Bowen, Neill, \& Crisp, 2016).

Outdoor education (OE) dapat mencakup kegiatan problem-solving activities, ropes challenge seperti wall climbing, abseiling, rafting, dan caving (Bowen, Neill, \& Crisp, 2016). Wall climbing telah menjadi aktivitas belajar dalam outdoor education $(O E)$ serta menekankan pengembangan berbagai keterampilan sosial, emosional, dan kognitif berkontribusi terhadap perkembangan menyeluruh tanpa memandang usia (Deborah Bialeschki et al., 2016). Wallclimbing memiliki pengaruh positif pada perkembangan physical dan psychological (Sanchez, Lambert, Jones, \& Llewellyn, 2012). Fraser-Thomas, Côté, \& Deakin (2005) mengkategorikan manfaat dari wallclimbing untuk remaja terkait pengembangan fisik, sosial emosional, dan intelektual sebagai kerangka kerja.

Tan (2005) melakukan penelitian untuk mengetahui pengaruh dari outdoor education $(O E)$ terhadap time management, social competence, task leadership, emotional control, confidence dan active initiative hasilnya terdapat peningkatan secara signifikan terkecuali time management serta menunjukkan pengaruh positif dari outdoor education $(O E)$ dipertahankan untuk keterampilan dan kompetensi tertentu. Outdoor education (OE) diharapkan dapat melampaui pendidikan karakter serta menawarkan beragam kegiatan untuk memungkinkan siswa melatih social emotional competencies (Ee \& Ong, 2014). Social emotional competencies (SEC) terkait erat dalam membuat keputusan bertanggung jawab, memahami perasaan dan nilai seseorang, menghormati dan mempertimbangkan orang lain serta menetapkan sasaran adaptif (Payton et al., 2000).

Masa remaja ditinjau sebagai fase kehidupan menuntut berbagai perjuangan dan tantangan untuk diatasi, masa remaja ini adalah periode di mana seorang individu mengalami perubahan biologis, psikologis dan sosial, transisi buruk dari masa kanak-kanak ke masa dewasa dapat menyebabkan maladaptasi, perilaku beresiko, atau kenakalan remaja (Brand, 2002). Kenakalan remaja di Indonesia antara lain; melakukan tindakan kekerasan terhadap teman sebaya dilandasi permasalahan asmara (Detik Health, 2011). Masa remaja sebagai periode berpotensi dalam kehidupan individu menjadi rentan dan tertekan dalam kelangsungan hidup di masyarakat dan berdampak negatif pada kemampuan untuk mengembangkan keterampilan pro-sosial juga berhasil secara akademis (Akos \& Galassi, 2004; Shann, 2001; Limbos \& Casteel, 2008). Perkembangan psikologis dan emosional remaja lebih lambat dan bersifat tiba-tiba berubah oleh karena itu masalah emosional mengacu pada reaksi sadar dan di bawah sadar terhadap rangsangan lingkungan diikuti oleh evaluasi kognitif rangsangan dapat berupa rangsang positif atau rangsang negatif (Albert \& Steinberg, 2011; Lazarus, 2000).

Kerangka social emotional competencies (SEC) ini merupakan bagian dari pendidikan afektif dalam pengembangan individu remaja serta pembelajaran lingkungan dapat menghasilkan manfaat psikososial lebih luas (Berryhill \& Prinz, 2003). Social emotional competencies (SEC) tercermin dalam pengetahuan, keterampilan, dan sikap remaja untuk mengelola pikiran dan emosi secara konstruktif, mengelola tindakan mereka, dan memupuk hubungan baik (Vernon, Modecki, \& Barber, 2018). Social emotional competencies (SEC) dikaitkan dengan perilaku, prestasi akademik, dan hubungan lebih baik antara remaja dan teman sebaya serta kesehatan mental (Durlak, Weissberg, Dymnicki, Taylor, \& Schellinger, 2011). Outdoor education $(O E)$ integrasi social emotional learning memiliki potensi untuk memfasilitasi social emotional competencies (SEC) dalam jangka 
pendek (Brookes, 2003) atau jangka panjang (Barwick, 2004). Implikasi dari temuan ini perlu dilakukan studi untuk membantu institusi sekolah mengembangkan social emotional competencies (SEC) siswa (Ee \& Ong, 2014).

\section{METODE PENELITIAN}

Berdasarkan desain penelitian yaitu pretest - posttest control group design with more than one experimental sehingga dalam pengambilan sampel adalah teknik purposive sampling dilihat dari usia para sampel. Sehingga diperoleh sampel berusia 15-17 tahun dan harus menggunakan 20 orang sampel dari setiap kelompok maka jumlah total 60 orang berdasarkan sampel sedang menempuh pendidikan di sekolah menengah atas. Seperti dinyatakan oleh Fraenkel, Wallen, \& Hyun (2012:271) "provided there are at least 20 subjects in each group".

Setelah pretest, treatment dilakukan selama 8 pertemuan dengan frekuensi 2 kali pertemuan setiap minggunya. Penerapan program aktivitas outdoor education (wall climbing integrasi social emotional learning) pada kelompok eksperimen I, program aktivitas outdoor education (wall climbing) non-integrasi kelompok eksperimen II, dan aktivitas pembelajaran ekstrakurikuler akademis kelompok kontrol dilakukan sesuai tahapan pada proses kegiatannya. Setelah treatment lalu diadakan posttest, tes ini dilakukan untuk melihat social emotional competencies siswa setelah diberikan treatment. Sehingga total menjadi 12 pertemuan, hal ini sesuai dengan paparan Neill \& Richards (1998) berpendapat bahwa "Particularly strong outcomes were evident for the long (3 - 4 weeks) outward bound programs with young adults". Hal ini menunjukkan bahwa 3 - 4 minggu program outdoor education dapat mengembangkan bagian penting dari physical, social, intellectual, and emotional development.

Kuesioner social emotional competencies (SEC) diberikan dua kali pada pretest dan posttest, diadaptasi dari SECQ (social emotional competencies questionnaire) (Zhou \& Ee, 2012). Siswa menilai tanggapan mereka pada skala Likert enam poin dengan $1=$ 'sangat tidak setuju' dan $6=$ 'Sangat setuju'. Validitas SECQ (social emotional competencies questionnaire) diuji menggunakan analisis faktor konfirmatori dengan nilai lebih besar dari 0.90 menunjukkan kesesuaian model dapat diterima. Kemudian SECQ (social emotional competencies questionnaire) diuji kembali validitas bahasa melalui teoritical validity dan face validity oleh Balai Bahasa Universitas Pendidikan Indonesia \& English Prestasi Learning Center (2019) dengan nilai kesesuaian 0.90 menunjukan kriteria sangat valid dan dapat digunakan tanpa revisi (Kline, 2005).

SECQ (social emotional competencies questionnaire) memiliki reliabilitas tinggi dengan koefisien reliabilitas sub variable self-awareness (kesadaran diri) 0.91, social awareness (kesadaran sosial) 0.87, self-management (manajemen diri) 0.84, relationship management (manajemen hubungan) 0.91 dan responsible decisionmaking (pengambilan keputusan bertanggung jawab) 0.85 (Zhou \& Ee, 2012).

Dalam mengolah dan menganalisis data, peneliti menggunakan analisis data ANOVA, pengolahan data tersebut digunakan mengacu pada penelitian oleh (Pan, 2010) dengan kriteria penerimaan $\alpha=0,05$. Pengolahan data menggunakan ANOVA dilakukan karena data dalam penelitian ini berdistribusi normal dan memiliki variansi data homogen, sebelumnya sudah di olah menggunakan uji kolmogorov-smirnof untuk uji normalitas dan levine test untuk uji homogenitas data. Pengolahan data dalam penelitian ini dibantu dengan software SPSS v.23 for windows.

\section{HASIL DAN PEMBAHASAN 3.1 Hasil}

Perolehan rata-rata dan simpangan baku social emotional competencies (SEC) siswa pada saat pretest dan posttest pada kelompok eksperimen satu (1), kelompok eksperimen dua (2), dan kelompok kontrol disajikan pada tabel berikut: 
Tabel 1. Perolehan rata-rata dan simpangan baku (secq)

\begin{tabular}{cccc}
\hline & Kelompok Penelitian & Pretest $\boldsymbol{\pi} / \boldsymbol{\sigma}$ & Posttest $\boldsymbol{\pi} / \boldsymbol{\sigma}$ \\
\cline { 2 - 4 } SECQ & $\pi=5,21$ & $\pi=5,39$ \\
\multirow{2}{*}{ Eksperimen 1 } & $\sigma=0,37$ & $\sigma=0,14$ \\
\cline { 2 - 4 } & \multirow{2}{*}{ Eksperimen 2 } & $\pi=4,22$ & $\pi=4,17$ \\
& $\sigma=0,40$ & $\sigma=0,46$ \\
\hline \multirow{2}{*}{ Kontrol } & $\pi=1,92$ & $\pi=2,07$ \\
& $\sigma=0,28$ & $\sigma=0,38$ \\
\hline
\end{tabular}

Berdasarkan pada tabel 1 dapat dilihat bahwa nilai rata-rata kelompok eksperimen satu (1) outdoor education (wall climbing diintegrasikan social emotional learning), kelompok eksperimen dua (2) outdoor education (wall climbing), dan kelompok kontrol (aktivitas pembelajaran ekstrakurikuler akademis) dalam social emotional competencies (SEC) mengalami peningkatan dan penurunan pada nilai posttest.

Pada pretest kelompok eksperimen satu (1) outdoor education (wall climbing diintegrasikan social emotional learning) dalam social emotional competencies (SEC) diperoleh nilai rata-rata $(\boldsymbol{\pi}=5,21)$ dengan simpangan baku $(\sigma=0,37)$ dan mengalami peningkatan pada saat posttest dengan nilai rata-rata $(\boldsymbol{\pi}=5,39)$ dengan rentang skor 0,18 dan nilai simpangan baku $(\sigma=$ 0,14 ) dengan rentang skor 0,23 .

Pada pretest kelompok eksperimen dua (2) outdoor education (wall climbing) dalam social emotional competencies (SEC) diperoleh nilai rata-rata $(\boldsymbol{\pi}=4,22)$ dengan simpangan baku $(\sigma=0,40)$ dan mengalami penurunan pada saat posttest dengan nilai rata-rata $(\boldsymbol{\pi}=4,17)$ dengan rentang skor 0,05 dan nilai simpangan baku $(\sigma=$ $0,46)$ dengan rentang skor 0,06 .

Pada pretest kelompok kontrol (aktivitas pembelajaran ekstrakurikuler akademis) dalam social emotional competencies (SEC) diperoleh nilai ratarata $(\boldsymbol{\pi}=1,92)$ dengan simpangan baku $(\boldsymbol{\sigma}$ $=0,28)$ dan mengalami peningkatan pada saat posttest dengan nilai rata-rata $(\boldsymbol{\pi}=2,07)$ dengan rentang skor 0,15 dan nilai simpangan baku $(\sigma=0,38)$ dengan rentang skor 0,10 .

Perolehan rata-rata dan simpangan baku lima komponen social emotional competencies (SEC): (1) kesadaran diri (self-awareness); (2) kesadaran sosial (social awareness); (3) manajemen diri (self-management); (4) manajemen hubungan (relationship management) dan; (5) pengambilan keputusan bertanggung jawab (responsible decision making) siswa saat pretest dan posttest pada kelompok eksperimen satu (1), kelompok eksperimen dua (2), dan kelompok kontrol disajikan pada tabel sebagai berikut :

Tabel 2. Perolehan rata-rata dan simpangan baku (self-awareness)

\begin{tabular}{cccc}
\hline SECQ & Kelompok Penelitian & Pretest $\boldsymbol{\pi} / \boldsymbol{\sigma}$ & Posttest $\boldsymbol{\pi} / \boldsymbol{\sigma}$ \\
\hline \multirow{3}{*}{$\begin{array}{c}\text { Self- } \\
\text { Awareness }\end{array}$} & Eksperimen 1 & $\pi=5,21$ & $\pi=5,46$ \\
& \multirow{2}{*}{ Eksperimen 2 } & $\sigma=0,32$ & $\sigma=0,22$ \\
\cline { 2 - 4 } & \multirow{2}{*}{ Kontrol } & $\sigma=0,43$ & $\pi=4,65$ \\
& & $\pi=2,11$ & $\pi=0,41$ \\
\cline { 2 - 4 } & & $\sigma=0,44$ & $\sigma=0,49$
\end{tabular}

Berdasarkan pada tabel 2 dapat dilihat bahwa nilai rata-rata kelompok eksperimen satu (1) outdoor education (wall climbing diintegrasikan social emotional learning), kelompok eksperimen dua (2) outdoor education (wall climbing), dan kelompok kontrol (aktivitas pembelajaran ekstrakurikuler akademis) dalam kompetensi self-Awareness mengalami peningkatan dan penurunan pada nilai posttest.

Pada pretest kelompok eksperimen satu (1) outdoor education (wall climbing 
diintegrasikan social emotional learning) dalam kompetensi self-Awareness diperoleh nilai ratarata $(\boldsymbol{\pi}=5,21)$ dengan simpangan baku $(\boldsymbol{\sigma}=$ $0,32)$ dan mengalami peningkatan pada saat posttest dengan nilai rata-rata $(\boldsymbol{\pi}=5,46)$ dengan rentang skor 0,25 dan nilai simpangan baku $(\sigma=$ 0,22 ) dengan rentang skor 0,10 .

Pada pretest kelompok eksperimen dua (2) outdoor education (wall climbing) dalam kompetensi self-Awareness diperoleh nilai rata-rata $(\pi=4,52)$ dengan simpangan baku $(\sigma=0,43)$ dan mengalami peningkatan pada saat posttest dengan nilai rata-rata $(\pi=4,65)$ dengan rentang skor 0,13 dan nilai simpangan baku $(\boldsymbol{\sigma}=0,41)$ dengan rentang skor 0,02 .

Pada pretest kelompok kontrol (aktivitas pembelajaran ekstrakurikuler akademis) dalam kompetensi self-Awareness diperoleh nilai rata-rata $(\boldsymbol{\pi}=2,11)$ dengan simpangan baku $(\sigma=0,44)$ dan mengalami penurunan pada saat posttest dengan nilai rata-rata $(\boldsymbol{\pi}=1,90)$ dengan rentang skor 0,21 dan nilai simpangan baku $(\boldsymbol{\sigma}=0,49)$ dengan rentang skor 0,05 .

Tabel 3. Perolehan rata-rata dan simpangan baku (social-awareness)

\begin{tabular}{cccc}
\hline SECQ & Kelompok Penelitian & Pretest $\boldsymbol{\pi} / \boldsymbol{\sigma}$ & Posttest $\boldsymbol{\pi} / \boldsymbol{\sigma}$ \\
\hline \multirow{3}{*}{$\begin{array}{c}\text { Social- } \\
\text { Awareness }\end{array}$} & Eksperimen 1 & $\pi=5,13$ & $\pi=5,25$ \\
\cline { 2 - 4 } & \multirow{2}{*}{ Eksperimen 2 } & $\pi=3,42$ & $\sigma=0,19$ \\
\cline { 2 - 4 } & \multirow{2}{*}{ Kontrol } & $\sigma=0,71$ & $\pi=3,67$ \\
& & $\pi=0,73$ \\
\hline
\end{tabular}

Berdasarkan pada tabel 3 dapat dilihat bahwa nilai rata-rata kelompok eksperimen satu (1) outdoor education (wall climbing diintegrasikan social emotional learning), kelompok eksperimen dua (2) outdoor education (wall climbing), dan kelompok kontrol (aktivitas pembelajaran ekstrakurikuler akademis) dalam kompetensi social-awareness mengalami peningkatan dan penurunan pada nilai posttest.

Pada pretest kelompok eksperimen satu (1) outdoor education (wall climbing diintegrasikan social emotional learning) dalam kompetensi social-awareness diperoleh nilai rata-rata $(\boldsymbol{\pi}=5,13)$ dengan simpangan baku $(\sigma=0,42)$ dan mengalami peningkatan pada saat posttest dengan nilai rata-rata $(\boldsymbol{\pi}=5,25)$ dengan rentang skor 0,12 dan nilai simpangan baku $(\sigma=0,19)$ dengan rentang skor 0,23 .

Pada pretest kelompok eksperimen dua (2) outdoor education (wall climbing) dalam kompetensi social-awareness diperoleh nilai rata-rata $(\boldsymbol{\pi}=3,70)$ dengan simpangan baku $(\sigma=0,71)$ dan mengalami penurunan pada saat posttest dengan nilai rata-rata $(\boldsymbol{\pi}=3,67)$ dengan rentang skor 0,03 dan nilai simpangan baku $(\sigma=0,73)$ dengan rentang skor 0,02 .

Pada pretest kelompok kontrol (aktivitas pembelajaran ekstrakurikuler akademis) dalam kompetensi socialawareness diperoleh nilai rata-rata $(\pi=$ 1,92) dengan simpangan baku $(\sigma=0,46)$ dan mengalami penurunan pada saat posttest dengan nilai rata-rata $(\boldsymbol{\pi}=1,67)$ dengan rentang skor 0,25 dan nilai simpangan baku $(\sigma=0,47)$ dengan rentang skor 0,01 .

Tabel 4. Perolehan rata-rata dan simpangan baku (self-management)

\begin{tabular}{cccc}
\hline SECQ & Kelompok Penelitian & Pretest $\boldsymbol{\pi} / \boldsymbol{\sigma}$ & Posttest $\boldsymbol{\pi} / \boldsymbol{\sigma}$ \\
\hline \multirow{3}{*}{$\begin{array}{c}\text { Self- } \\
\text { Management }\end{array}$} & Eksperimen 1 & $\pi=5,18$ & $\pi=5,28$ \\
& \multirow{2}{*}{ Eksperimen 2 } & $\sigma=0,38$ & $\sigma=0,27$ \\
\cline { 2 - 4 } & & $\pi=4,05$ & $\pi=3,87$ \\
& \multirow{2}{*}{ Kontrol } & $\sigma=0,71$ & $\sigma=0,84$ \\
\hline
\end{tabular}


Berdasarkan pada tabel 4 dapat dilihat bahwa nilai rata-rata kelompok eksperimen satu(1) outdoor education (wall climbing diintegrasikan social emotional learning), kelompok eksperimen dua (2) outdoor education (wall climbing), dan kelompok kontrol (aktivitas pembelajaran ekstrakurikuler akademis) dalam kompetensi self-management mengalami peningkatan dan penurunan pada nilai posttest.

Pada pretest kelompok eksperimen satu (1) outdoor education (wall climbing diintegrasikan social emotional learning) dalam kompetensi self-management diperoleh nilai rata-rata $(\boldsymbol{\pi}=5,18)$ dengan simpangan baku $(\boldsymbol{\sigma}=0,38)$ dan mengalami peningkatan pada saat posttest dengan nilai rata-rata $(\boldsymbol{\pi}=5,28)$ dengan rentang skor 0,10 dan nilai simpangan baku $(\sigma=0,27)$ dengan rentang skor 0,11 .

Pada pretest kelompok eksperimen dua (2) outdoor education (wall climbing) dalam kompetensi self-management diperoleh nilai rata-rata $(\boldsymbol{\pi}=4,05)$ dengan simpangan baku $(\sigma=0,71)$ dan mengalami penurunan pada saat posttest dengan nilai rata-rata $(\boldsymbol{\pi}=3,87)$ dengan rentang skor 0,18 dan nilai simpangan baku $(\sigma=0,84)$ dengan rentang skor 0,13 .

Pada pretest kelompok kontrol (aktivitas pembelajaran ekstrakurikuler akademis) dalam kompetensi selfmanagement diperoleh nilai rata-rata $(\boldsymbol{\pi}=$ $2,19)$ dengan simpangan baku $(\sigma=0,67)$ dan mengalami penurunan pada saat posttest dengan nilai rata-rata $(\boldsymbol{\pi}=1,97)$ dengan rentang skor 0,22 dan nilai simpangan baku $(\sigma=0,55)$ dengan rentang skor 0,12 .

Tabel 5. Perolehan rata-rata dan simpangan baku (relationship management)

\begin{tabular}{cccc}
\hline SEC $Q$ & Kelompok Penelitian & Pretest $\boldsymbol{\pi} / \boldsymbol{\sigma}$ & Posttest $\boldsymbol{\pi} / \boldsymbol{\sigma}$ \\
\hline \multirow{2}{*}{ Relationship } & Eksperimen 1 & $\pi=5,33$ & $\pi=5,52$ \\
Management & Eksperimen 2 & $\pi=0,42$ & $\sigma=0,28$ \\
\cline { 2 - 4 } & & $\sigma=0,83$ & $\pi=4,28$ \\
\cline { 2 - 4 } & \multirow{2}{*}{ Kontrol } & $\pi=2,04$ & $\pi=1,94$ \\
& & $\sigma=0,57$ & $\sigma=0,49$ \\
\hline
\end{tabular}

Berdasarkan pada tabel 5 dapat dilihat bahwa nilai rata-rata kelompok eksperimen satu (1) outdoor education (wall climbing diintegrasikan social emotional learning), kelompok eksperimen dua (2) outdoor education (wall climbing), dan kelompok kontrol (aktivitas pembelajaran ekstrakurikuler akademis) dalam kompetensi relationship management mengalami peningkatan dan penurunan pada nilai posttest.

Pada pretest kelompok eksperimen satu (1) outdoor education (wall climbing diintegrasikan social emotional learning) dalam kompetensi relationship management diperoleh nilai rata-rata $(\boldsymbol{\pi}=5,33)$ dengan simpangan baku $(\sigma=0,42)$ dan mengalami peningkatan pada saat posttest dengan nilai rata-rata $(\boldsymbol{\pi}=5,52)$ dengan rentang skor 0,19 dan nilai simpangan baku $(\sigma=0,28)$ dengan rentang skor 0,14 .

Pada pretest kelompok eksperimen dua (2) outdoor education (wall climbing) dalam kompetensi relationship management diperoleh nilai rata-rata $(\pi=4,26)$ dengan simpangan baku $(\sigma=0,83)$ dan mengalami peningkatan pada saat posttest dengan nilai rata-rata $(\boldsymbol{\pi}=4,28)$ dengan rentang skor 0,02 dan nilai simpangan baku $(\sigma=0,65)$ dengan rentang skor 0,20 .

Pada pretest kelompok kontrol (aktivitas pembelajaran ekstrakurikuler akademis) dalam kompetensi relationship management diperoleh nilai rata-rata $(\boldsymbol{\pi}$ $=2,04)$ dengan simpangan baku $(\sigma=$ $0,57)$ dan mengalami penurunan pada saat posttest dengan nilai rata-rata $(\boldsymbol{\pi}=$ $1,94)$ dengan rentang skor 0,10 dan nilai simpangan baku $(\sigma=0,49)$ dengan rentang skor 0,08 . 
Tabel 6. Perolehan rata-rata dan simpangan baku (responsible-decision making)

\begin{tabular}{cccc}
\hline SECQ & Kelompok Penelitian & Pretest $\boldsymbol{\pi} / \boldsymbol{\sigma}$ & Posttest $\boldsymbol{\pi} / \boldsymbol{\sigma}$ \\
\hline \multirow{2}{*}{ Eksperimen 1 } & $\pi=5,22$ & $\pi=5,45$ \\
Responsible- & \multirow{2}{*}{ Eksperimen 2 } & $\pi=0,52$ & $\sigma=0,23$ \\
\cline { 2 - 4 } Decision Making & \multirow{2}{*}{ Kontrol } & $\sigma=1,33$ & $\pi=4,61$ \\
\cline { 2 - 4 } & & $\pi=2,11$ & $\sigma=0,40$ \\
\cline { 2 - 4 } & & $\sigma=0,39$ & $\pi=2,11$ \\
& & $\sigma=0,30$ \\
\hline
\end{tabular}

Berdasarkan pada tabel 6 dapat dilihat bahwa nilai rata-rata kelompok eksperimen satu (1) outdoor education (wall climbing diintegrasikan social emotional learning), kelompok eksperimen dua (2) outdoor education (wall climbing), dan kelompok kontrol (aktivitas pembelajaran ekstrakurikuler akademis) dalam kompetensi responsible-decision making mengalami peningkatan, penurunan pada nilai posttest.

Pada pretest kelompok eksperimen satu (1) outdoor education (wall climbing diintegrasikan social emotional learning) dalam kompetensi responsible-decision making diperoleh nilai rata-rata $(\pi=5,22)$ dengan simpangan baku $(\sigma=0,52)$ dan mengalami peningkatan pada saat posttest dengan nilai rata-rata $(\boldsymbol{\pi}=5,45)$ dengan rentang skor 0,23 dan nilai simpangan baku $(\boldsymbol{\sigma}=0,23)$ dengan rentang skor 0,29 .

Pada pretest kelompok eksperimen dua (2) outdoor education (wall climbing) dalam kompetensi responsible-decision making diperoleh nilai rata-rata $(\boldsymbol{\pi}=4,33)$ dengan simpangan baku $(\sigma=1,10)$ dan mengalami peningkatan pada saat posttest dengan nilai rata-rata $(\boldsymbol{\pi}=4,61)$ dengan rentang skor 0,28 dan nilai simpangan baku $(\sigma=0,40)$ dengan rentang skor 0,70 .

Pada pretest kelompok kontrol (aktivitas pembelajaran ekstrakurikuler akademis) dalam kompetensi responsibledecision making diperoleh nilai rata-rata $(\boldsymbol{\pi}$ $=2,11)$ dengan simpangan baku $(\sigma=0,39)$ dan mengalami penurunan pada saat posttest dengan nilai rata-rata $(\boldsymbol{\pi}=2,11)$ dan nilai simpangan baku $(\boldsymbol{\sigma}=0,30)$ dengan rentang skor 0,09 .

Pengujian ANOVA dilakukan untuk mengetahui perbedaan pengaruh antara tiga kelompok, hasilnya menunjukan nilai sig. social emotional competencies adalah 0,000 $<0,05$ maka $H_{0}$ ditolak. Artinya terdapat perbedaan pengembangan social emotional competencies melalui outdoor education. Perbedaan antara ketiga kelompok tersebut dapat dilihat pada hasil tabel post hoc dengan uji LSD berikut ini:

Tabel 7. Hasil uji LSD

\begin{tabular}{llcccccc}
\hline \multirow{2}{*}{$\begin{array}{c}\text { (I) Eksperimen } \\
\text { (SECQ) }\end{array}$} & $\begin{array}{c}\text { (J) Eksperimen } \\
\text { (SECQ) }\end{array}$ & $\begin{array}{c}\text { Mean } \\
\text { Difference } \\
\text { (I-J) }\end{array}$ & $\begin{array}{c}\text { Std. } \\
\text { Error }\end{array}$ & Sig. & & \multicolumn{2}{c}{$\begin{array}{c}\text { 95\% Confidence } \\
\text { Interval }\end{array}$} \\
\hline \multirow{2}{*}{ Eksperimen I } & Eksperimen II & $1,17600^{*}$ &, 09227 &, 000 &, 9912 & $\begin{array}{c}\text { Upper } \\
\text { Bound }\end{array}$ & Bound \\
\hline \multirow{2}{*}{ Eksperimen II } & Kontrol & Eksperimen I & $-1,17600^{*}$ &, 09227 &, 000 & $-1,3608$ &,- 9912 \\
& Kontrol & $2,29800^{*}$ &, 09227 &, 000 & 2,1132 & 2,4828 \\
\hline \multirow{2}{*}{ Kontrol } & Ekperimen I & $-3,47400^{*}$ &, 09227 &, 000 & $-3,6588$ & $-3,2892$ \\
& Eksperimen II & $-2,29800^{*}$ &, 09227 &, 000 & $-2,4828$ & $-2,1132$ \\
\hline
\end{tabular}

Berdasarkan tabel 7 nilai sig. social emotional competencies adalah $0,000<0,05$ maka $H_{0}$ ditolak. Artinya terdapat perbedaan skor pengembangan social emotional competencies melalui outdoor education.

\subsection{Pembahasan}

Pada penelitian ini, terbagi ke dalam tiga kelompok penelitian yaitu kelompok eksperimen satu (1) diberi perlakuan aktivitas outdoor education (wall climbing 
integrasi social emotional learning), kelompok eksperimen dua (2) dengan perlakuan outdoor education (wall climbing) non-integrasi, dan kelompok kontrol dengan aktivitas pembelajaran ekstrakurikuler akademis. Hasil temuan menunjukan bahwa kelompok eksperimen satu (1) lebih unggul dalam mengembangkan social emotional competencies siswa dibandingkan dengan kelompok eksperimen dua (2) dan kelompok kontrol. Hal tersebut dibuktikan dengan perhitungan ANOVA dan t-hitung pada masing-masing kelompok.

Dimana kelompok eksperimen satu (1) dan eksperimen dua (2) memiliki nilai t hitung $20>1,684$ nilai t-tabel, sehingga terdapat hasil signifikan antara kelompok eksperimen satu (1) dan eksperimen dua (2). Artinya, besaran perbedaan terjadi antara kelompok eksperimen satu (1) diberi perlakuan outdoor education (wall climbing integrasi dengan social emotional learning) dan kelompok eksperimen dua (2) hanya diberi perlakuan outdoor education (wall climbing) yaitu sebesar 20.

Kelompok eksperimen satu (1) dan kelompok kontrol memiliki nilai $\mathrm{t}$ hitung $38,66>1,684$ nilai t-tabel, sehingga terdapat hasil signifikan antara kelompok eksperimen satu (1) dan kelompok kontrol. Maka besaran perbedaan terjadi antara kelompok eksperimen satu (1) diberi perlakuan outdoor education (wall climbing integrasi dengan social emotional learning) dan kelompok eksperimen dua (2) dan kelompok kontrol juga memiliki nilai t hitung $23>1,684$ nilai t-tabel, sehingga terdapat hasil signifikan antara kelompok eksperimen dua (2) dan kelompok kontrol. Dapat disimpulkan bahwa besaran perbedaan terjadi antara kelompok eksperimen dua (2) diberi perlakuan outdoor education (wall climbing) dan kelompok kontrol diberi aktivitas pembelajaran ekstrakurikuler akademis yaitu sebesar 23.

Hal menarik, pemikiran kita samasama diperlengkapi untuk mempelajari keterampilan dan konten berkaitan dengan perilaku dan emosi sosial, atau sekarang disebut pembelajaran social emotional learning (SEL). Selain itu, studi penelitian telah menunjukkan bahwa semua bentuk pembelajaran, baik akademik, sosial, atau emosional, terkaiterat(Zins, Weissberg, Wang, \& Walberg, 2004). Dinyatakan dengan cara lain: bagaimana perasaan kita memengaruhi cara berpikir kita, dan sebaliknya, bagaimana perasaan kita memengaruhi perasaan kita. Lebih lanjut, para peneliti telah menemukan bahwa pengajaran dalam social emotional learning (SEL) sama pentingnya dengan perkembangan dan keberhasilan sekolah sebagai pengajaran akademis. Sebagai contoh, dalam studi penting dari program social emotional learning (SEL) pada siswa sekolah menengah atas, Taylor, Oberle, Durlak, \& Weissberg (2017) menemukan bahwa siswa menerima instruksi dan program dukungan sosial dan emosional memperoleh poin tinggi dalam kinerja akademik, keterampilan sosial, keterampilan perilaku, dan sikap lebih dari siswa tidak menerima program ini. Studi ini, memberikan argumen meyakinkan untuk integrasi social emotional learning (SEL) ke dalam materi pembelajaran.

Greenberg, Kolasi, Hegsted, Berkowitz, \& Jurist (2017); CASEL, (2017) prinsip-prinsip integrasi social emotional learning (SEL) dirancang untuk membantu para guru, sekolah, dan tutor untuk mempromosikan pengembangan siswa dari kompetensi social emotional learning (SEL). Setiap prinsip mendukung satu atau lebih dari kompetensi inti social emotional learning (SEL) yaitu : (1) Selfawareness, kapasitas untuk merefleksikan perasaan, nilai, dan perilaku seseorang; (2) Social awareness, kemampuan untuk melihat situasi dari perspektif lain, menghormati norma sosial dan budaya orang lain, dan merayakan keberagaman; (3) Relationship skills, kemampuan untuk memulai dan mempertahankan hubungan positif dengan teman sebaya, guru, keluarga, dan masyarakat; (4) Self-management, serangkaian keterampilan mencakup self-motivation, goal-setting, personal organization, selfdiscipline, impulse control, dan penggunaan strategi untuk mengatasi stres; Responsible decision-making, kemampuan untuk membuat pilihan mempertimbangkan 
kesejahteraan diri sendiri dan orang lain. McGraw Hill (2018) prinsip-prinsip panduan berikut dapat digunakan untuk memandu perencanaan dan pengajaran social emotional learning (SEL) : (1) Create, Penciptaan lingkungan aman dan positif adalah fondasi dari semua upaya social emotional learning (SEL), baik di dalam maupun di luar ruang kelas. Meskipun setiap sekolah dan setiap kelas akan menerapkan prinsip ini secara berbeda, banyak memilih untuk menerapkan satu atau lebih dari strategi sama, seperti : (a) Sambut setiap siswa dengan nama; (b) Secara kolaboratif kembangkan aturan dan ekspektasi kelas dengan siswa; (c) Imbaulah siswa untuk meminta pertanggungjawaban satu sama lain atas pertemuan interaksi perilaku dan sosial; (d) Berikan beberapa cara bagi siswa untuk melaporkan, mendiskusikan, dan mengatasi konflik; (e) Hadiahi perilaku positif seperti menunjukkan rasa hormat; (6) Menetapkan kebijakan anti-intimidasi di seluruh sekolah, dan memantau semua lingkungan sekolah, termasuk taman bermain, kamar mandi, dan kafetaria; (2) Integrate, Faktanya, outdoor education (wall climbing) mendukung jenis integrasi ini, karena begitu banyak proses afektif terlibat dalam konten pembelajaran seperti emosi, perilaku, dan pengambilan keputusan. Pendekatan untuk integrasi social emotional learning (SEL) bervariasi tergantung pada kebutuhan pembelajaran dan sumber daya tersedia, tetapi harus mencakup konten dan peluang pemecahan masalah relevan dengan kehidupan siswa, yaitu : (a) Pilih konten dengan topik social emotional learning (SEL) terkait untuk digunakan dalam pembelajaran; (b) Menawarkan proyek berbasis masalah berdasarkan topik minat siswa; (c) Merancang pembelajaran berdasarkan tema kehidupan nyata (mis. Membantu antar siswa dalam meningkatkan kelestarian lingkungan); (d) Tunjukkan bagaimana keterampilan afektif, seperti interaksi sosial positif dan konstruktif; (e) Menciptakan kegiatan memungkinkan siswa untuk mengekspresikan emosi di tempat aman; (f) Metakognisi (memikirkan pemikiran sendiri) adalah bagian penting dari social emotional learning (SEL). Semua instruksi area konten dapat ditingkatkan dengan menawarkan peluang untuk refleksi diri pada pemecahan masalah siswa sendiri, pemilihan alat, strategi dan proses pemikiran lainnya; (3) Communicate, Implementasi social emotional learning (SEL) efektif bukanlahusahasendirian.Untukmenyediakan lingkungan belajar sosial dan emosional yang kaya, semua pemangku kepentingan harus menggunakan kompetensi social emotional learning (SEL) mereka sendiri, dimulai dengan komunikasi kuat dan pembentukan visi social emotional learning (SEL) solid. Bagaimana memulainya? Pertama-tama dapat membantu mengidentifikasi setiap dan semua pemangku kepentingan akan terlibat dalam social emotional learning (SEL). Ini termasuk : (a) Siswa; (b) Keluarga; (c) Guru; (d) Perangkat administrasi sekolah; (e) Masyarakat. Semua pemangku kepentingan ini adalah bagian dari pekerjaan penting pembelajaran sosial dan emosional, dan komunikasi kuat akan membantu memastikan bahwa para siswa mendapatkan manfaat penuh dari pemrograman social emotional learning (SEL); (4) Instruct, seperti halnya dengan konten akademik, pembelajaran sosial dan emosional dicapai melalui instruksi dan praktik. Meskipun banyak keterampilan SEL mungkin tampak intuitif atau mudah bagi orang dewasa, keterampilan baru, membingungkan, dan tidak dikenal oleh siswa. Dengan memberikan panduan dan instruksi eksplisit, guru dapat memastikan bahwa siswa memiliki pemahaman jelas tentang konten dan tujuan social emotional learning (SEL); (5) Empower, Untuk mendapatkan manfaat penuh dari social emotional learning (SEL), adalah penting bahwa siswa dari segala usia ditawari kesempatan berkesinambungan untuk menerapkan apa telah mereka pelajari. Guru dan staf sekolah lainnya dapat membantu perkembangan ini dengan menciptakan budaya pemberdayaan siswa. Ini tidak berarti bahwa orang dewasa harus menyerahkan kendali penuh atas apa terjadi di sekolah. Sebaliknya, orang dewasa dapat menghabiskan sebagian hari sekolah sebagai fasilitator, sambil membantu siswa 
membangun lingkungan positif dan aman serta memberikan bimbingan dan dukungan sesuai kebutuhan.

Terdapat 5 (lima) komponen social emotional competencies diintegrasikan dalam aktivitas outdoor education (wall climbing) penelitian ini, yaitu Bridgeland et al., (2013): (a) self-awareness, kemampuan untuk secara akurat mengenali emosi dan pikiran seseorang terhadap perilaku, salah satunya ketika practiceofbelay and climb saat siswa pertama (climber) melakukan pemanjatan pada area panjat tebing buatan dengan ketinggian 12 meter dan siswa kedua (belayer) melakukan pengamanan terhadap siswa pertama (climber) pada situasi dan kondisi tersebut siswa kedua (belayer) harus mengamati setiap pergerakan siswa pertama (climber) apakah akan terjatuh atau melanjutkan pemanjatan sampai selesai secara akurat dan mengenali emosi dari kebutuhan siswa pertama (climber) mulai dari distribusi tali, lock-system saat terjatuh sehingga tidak membebani kepada siswa pertama (climber) karena adanya komunikasi antara kedua siswa secara emosional; (b) social awareness, mengambil perspektif dan berempati dengan orang lain dari berbagai latar belakang dan budaya, etika dan perilaku antara lain ketika melakukan installation satu dan siswa lain bekerja sama dalam prosedur pengamanan mulai dari tali, pengaman tubuh, pengaman sisip pada area panjat tebing buatan lalu saling membantu sama lain apabila ada kesulitan tanpa adanya melihat suku, agama, dan ras sehingga terciptanya empati, etika dan perilakubaik;(c)self-management, kemampuan untuk mengatur emosi, pikiran, dan perilaku seseorang secara efektif dalam situasi berbeda. Ini termasuk mengelola stres, memotivasi diri sendiri misalnya practice of technique climbing memerlukan banyak gerakan beragam secara bersamaan, ketika siswa melakukan gerakan lengan dan kaki berirama dan mengelola stress agar tidak terjatuh dan memotivasi diri melakukan gerakan dengan baik sehingga dapat menyelesaikan suatu pemanjatan; (d) relationship management membangun dan memelihara hubungan sehat dan bermanfaat dengan beragam individu dan kelompok. Ini termasuk berkomunikasi dengan jelas, mendengarkan secara aktif, bekerja sama, pada practice of belay procedure mengutamakan respons tanggap, akurat dan terukut dalam setiap langkah-langkah pengamanan pada pemanjatan, ketika siswa melakukan belaying membangun hubungan baik dengan siswa melakukan climbing mulai dari mengamati setiap pergerakan, komunikasi pada kebutuhan pemanjatan antara lain sistem alur tali melalui kerja sama baik sehingga pemanjatan berhasil dan selamat; (e) responsible-decision making, individu mengembangkan kemampuan mereka untuk membuat pilihan konstruktif tentang perilaku pribadi dan interaksi sosial. Di implementasikan dalam kegiatan tools checking merupakan pengkondisian peralatan sebelum dan sesudah pemanjatan agar dapat terlaksana dengan baik dan mengurangi hambatan maupun kendala terjadi selama kegiatan berlangsung nantinya, ketika siswa mempersiapkan peralatan dengan kelompoknya masingmasing untuk direncakan bagaimana peralatan tersedia lengkap tanpa adanya kekurangan peralatan untuk pemanjatan, memilih dan memilah secara runut dan konstruktif peralatan mana akan digunakan dan tidak digunakan agar pemanjatan berlangsung optimal. Siswa dihadapkan pada dinamika kelompok agar mereka mengendalikan perilaku pribadi dalam tools checking dan menghindari konflik dapat merugikan siswa dan kelompoknya melalui interaksi sosial paripurna.

Kendellen, Camiré, Bean, Forneris, \& Thompson (2016) terdapat kebutuhan untuk mengembangkan program pembelajaran untuk gurunantinyaakan membantudalammemahami bagaimana cara membuat program terstruktur secara terencana dalam suatu pembelajaran. Sehingga hasil penelitian ini dapat digunakan khusunya dalam pengembangan pedagogi olahraga dengan pemberian kontribusi untuk sebuah kurikulum kedepannya bahwa sebuah program terstruktur secara terencana dapat mengembangkan social emotional competencies siswa, khususnya pada penelitian ini yaitu menggunakan perlakuan aktivitas outdoor education diintegrasikan dengan social emotional competencies. Bean \& Forneris (2016) menunjukkan bahwa program terstruktur secara terencana memiliki skor lebih tinggi pada 
kualitas program dan pengembangan remaja secara positif dari pada program terstruktur secara tidak terencana, dengan skor program olahraga direncanakan secara signifikan lebih tinggi pada beberapa ukuran kualitas program dan pengembangan remaja positif dari pada program kepemimpinan.

\section{KESIMPULAN}

Penelitian ini berfokus pada terdapatnya pengaruh signifikan dari program outdoor education (wall climbing integrasi social emotional learning) secara sengaja dibuat (terstruktur) kemudian dalam prosesnya diintegrasi dengan komponen-komponen terdapat dalam social emotional learning, hal tersebut dilakukan agar terjadi pengembangan dalam social emotional competencies siswa khusunya di usia remaja. Berdasarkan hasil penelitian, dapat disimpulkan bahwa terdapat skor tinggi dan pengaruh signifikan dalam menerapkan outdoor education (wall climbing integrasi social emotional learning) terhadap pengembangan social emotional competencies siswa di usia remaja.

\section{DAFTAR PUSTAKA}

Akos, P., \& Galassi, J. P. (2004). Gender and Race as Variables in Psychosocial Adjustment to Middle and High School. The Journal of Educational Research, 98(2), 102-108. https://doi.org/10.3200/JOER.98.2.102108.

Albert, D., \& Steinberg, L. (2011). Judgment and Decision Making in Adolescence. Journal of Research on Adolescence, 21(1), 211-224. https://doi.org/10.1111/j.1532-7795.2010.00724.x.

Barwick, H. (2004). Young Males : Strengths-Based And Male-Focused Approaches A Review Of The Research And Best Evidence. New Zealand: Ministry of Youth Development.

Bean, C., \& Forneris, T. (2016). Examining the Importance of Intentionally Structuring the Youth Sport Context to Facilitate Positive Youth Development. Journal of Applied Sport Psychology, 28(4), 410-425. https:// doi.org/10.1080/10413200.2016.1164764.

Berryhill, J. C., \& Prinz, R. J. (2003). Environmental Interventions to Enhance Student Adjustment: Implications for Prevention. Prevention Science, 4(2), 65-87.

Bowen, D. J., Neill, J. T., \& Crisp, S. J. R. (2016). Wilderness adventure therapy effects on the mental health of youth participants. Evaluation and Program Planning, 58, 49-59. https://doi.org/10.1016/J. EVALPROGPLAN.2016.05.005.

Brand, D. (2002). A Longitudinal Study of the Effects of a Wilderness-Enhanced Program on Behaviour-Disordered Adolescents. Journal of Outdoor and Environmental Education, 6(1), 40-56. https://doi.org/10.1007/ BF03400743.

Brookes, M. (2003). Higher education: marketing in a quasi-commercial service industry. International Journal of Nonprofit and Voluntary Sector Marketing, 8(2), 134-142. https://doi.org/10.1002/nvsm.207.

Deborah Bialeschki, M., Fine, S. M., Bennett, T., Barbara Humberstone, by, Prince, H., Henderson Routledge, K. A., ... York, N. (2016). The Camp Experience: Learning through the Outdoors.

Detik Health. (2011). 10 Penyebab Kenakalan Remaja. Retrieved July 15, 2019, from Detik Health website: https:// health.detik.com/ibu-dan-anak-inspired-kid/d-1552483/10-penyebab-kenakalan-remaja.

Durlak, J. A., Weissberg, R. P., Dymnicki, A. B., Taylor, R. D., \& Schellinger, K. B. (2011). The Impact of Enhancing Students' Social and Emotional Learning: A Meta-Analysis of School-Based Universal Interventions. Child Development, 82(1), 405-432. https://doi.org/10.1111/j.1467-8624.2010.01564.x.

Ee, J., \& Ong, C. W. (2014). Which social emotional competencies are enhanced at a social emotional learning camp? Journal of Adventure Education and Outdoor Learning, 14(1), 24-41. https://doi.org/10.1080/1 4729679.2012.761945.

Fraenkel, J. R., Wallen, N. E., \& Hyun, H. H. (2012). How to Design and Evaluate Research in Education. In The McGraw-Hill Companies (Eighth Edi, Vol. 53). https://doi.org/10.1017/CBO9781107415324.004.

Fraser-Thomas, J. L., Côté, J., \& Deakin, J. (2005). Youth sport programs: an avenue to foster positive youth development. Physical Education \& Sport Pedagogy, 10(1), 19-40. https://doi.org/10.1080/17408980 42000334890.

Greenberg, D. M., Kolasi, J., Hegsted, C. P., Berkowitz, Y., \& Jurist, E. L. (2017). Mentalized affectivity: A new model and assessment of emotion regulation. PLOS ONE, 12(10), e0185264. https://doi. 
org/10.1371/journal.pone.0185264.

Kendall, S., Rodger, J., \& Laxton, C. (2015). Evaluation of Learning Away: Final Report. London: Paul Hamlyn Foundation.

Kendellen, K., Camiré, M., Bean, C., Forneris, T., \& Thompson, J. (2016). Integrating life skills into Golf Canada's youth programs: Insights into a successful research to practice partnership. Journal of Sport Psychology in Action, 8(1), 34-46. https://doi.org/10.1080/21520704.2016.1205699.

Kline, R. B. (2005). Principles and practice of structural equation modeling. New York: Guilford Press.

Lazarus, R. S. (2000). How Emotions Influence Performance in Competitive Sports. The Sport Psychologist, 14(1), 229-252.

Limbos, M. A. P., \& Casteel, C. (2008). Schools and Neighborhoods: Organizational and Environmental Factors Associated With Crime in Secondary Schools*. Journal of School Health, 78(10), 539-544. https://doi. org/10.1111/j.1746-1561.2008.00341.x.

Martin, P., \& Ho, S. (2009). Seeking resilience and sustainability: outdoor education in Singapore. Journal of Adventure Education \& Outdoor Learning, 9(1), 79-92. https://doi.org/10.1080/14729670802670167

Neill, J. T., \& Richards, G. E. (1998). Does Outdoor Education Really Work? A Summary Of Recent Meta-Analyses. Journal of Outdoor and Environmental Education, 3(1), 2-9. https://doi.org/10.1007/BF03400671.

Pan, C.-Y. (2010). Effects of water exercise swimming program on aquatic skills and social behaviors in children with autism spectrum disorders. Autism, 14(1), 9-28. https://doi.org/10.1177/1362361309339496.

Payton, J. W., Wardlaw, D. M., Graczyk, P. A., Bloodworth, M. R., Tompsett, C. J., \& Weissberg, R. P. (2000). Social and Emotional Learning: A Framework for Promoting Mental Health and Reducing Risk Behavior in Children and Youth. Journal of School Health, 70(5), 179-185.https://doi.org/10.1111/j.1746-1561.2000. tb06468.x.

Richmond, D., Sibthorp, J., Gookin, J., Annarella, S., \& Ferri, S. (2018). Complementing classroom learning through outdoor adventure education: out-of-school-time experiences that make a difference. Journal of Adventure Education and Outdoor Learning, 18(1), 36-52. https://doi.org/10.1080/14729679.2017. 1324313.

Sanchez, X., Lambert, P., Jones, G., \& Llewellyn, D. J. (2012). Efficacy of pre-ascent climbing route visual inspection in indoor sport climbing. Scandinavian Journal of Medicine \& Science in Sports, 22(1), 67-72. https://doi.org/10.1111/j.1600-0838.2010.01151.x.

Shann, M. H. (2001). Students' Use of Time Outside of School: A Case for After School Programs for Urban Middle School Youth. The Urban Review, 33(4), 339-356. https://doi.org/10.1023/A:1012248414119

Szczepanski, A. (2009). Outdoor Education - Authentic Learning in the Context of Urban and Rural Landscape - A Way of Connecting Environmental Education and Health to Sustainable Learning - Literary Education and Sensory Experience. Perspective of the Where, What, Why and When of Learning. 宮城学院女子大学発達科学研究, 2(1), 83-98.

Tan, M. (2005). Examining The Impact Of An Outward Bound Singapore Program On The Life Effectiveness Of Adolescents. University of New Hampshire.

Taylor, R. D., Oberle, E., Durlak, J. A., \& Weissberg, R. P. (2017). Promoting Positive Youth Development Through School-Based Social and Emotional Learning Interventions: A Meta-Analysis of Follow-Up Effects. Child Development, 88(4), 1156-1171. https://doi.org/10.1111/cdev.12864.

Vernon, L., Modecki, K. L., \& Barber, B. L. (2018). Mobile Phones in the Bedroom: Trajectories of Sleep Habits and Subsequent Adolescent Psychosocial Development. Child Development, 89(1), 66-77. https://doi. org/10.1111/cdev.12836.

Vroegop, J. (2014). Nature Connectedness \& Winter Camping: A Combination of Quantitative and Qualitative Approaches. Linkoping University.

Williams, I. R., Rose, L. M., Olsson, C. A., Patton, G. C., \& Allen, N. B. (2018). The impact of outdoor youth programs on positive adolescent development: Study protocol for a controlled crossover trial. International Journal of Educational Research, 87, 22-35. https://doi.org/10.1016/J.IJER.2017.10.004

Zhou, M., \& Ee, J. (2012). Development and validation of social emotional competency questionnaire. The International Journal of Emotional Education, 4(2), 27-42.

Zins, J. E., Weissberg, R. P., Wang, M. C., \& Walberg, H. J. (2004). Building Academic Success on Social and Emotional Learning: What Does the research say. New York: Teachers Collage Press. 